\title{
O processo de construção da Política Nacional de Atenção Integral à Saúde do Homem
}

\section{I ${ }^{1}$ Ana Paula Azevedo Hemmi, 2 Tatiana Wargas de Faria Baptista, ${ }^{3}$ Mônica de Rezende I}

Resumo: O artigo analisa o processo de construção da Política Nacional de Atenção Integral à Saúde do Homem, com vistas a reconhecer a participação dos diversos agentes sociais na formulação dessa política pública. Para tanto, busca identificar os eventos que precederam a construção do documento, as estratégias utilizadas para promover a participação dos diferentes grupos de interesse e os mecanismos para pactuação e tomada de decisão. Foram analisados documentos institucionais, referências acadêmicas, e realizadas entrevistas com agentes participantes do processo. Identificou-se que a intenção da política surge a partir da atuação da Sociedade Brasileira de Urologia. O Ministério da Saúde aproximou do processo político outros agentes, mas a leitura biomédica mantevese predominante. A forma de participação dos agentes pautou-se na transmissão de conhecimento, com pouco espaço para o enfrentamento de conflitos na construção da política, apesar de o documento final ser divulgado como expressão de consensos. Houve silenciamentos das contradiçóes e disputas que permearam a definição de saúde do homem.

> Palavras-chave: política pública; participação social; saúde do homem; política de saúde.

\author{
${ }^{1}$ Universidade Federal do \\ Vale do Jequitinhonha e \\ Mucuri. Diamantina-MG, Brasil \\ (anahemmi@gmail.com). ORCID \\ 0000-0003-3513-9523 \\ 2 Escola Nacional de Saúde Pública \\ Sergio Arouca, Fundação Oswaldo \\ Cruz. Rio de Janeiro-RJ, Brasil \\ (twargas@gmail.com). ORCID: \\ 0000-0002-3445-2027 \\ ${ }^{3}$ Instituto de Saúde Coletiva, \\ Universidade Federal Fluminense \\ Niterói-RJ, Brasil (m.rezende70@ \\ gmail.com). ORCID: 0000-0001- \\ 8710-4598
}

Recebido em: 13/02/2020

Aprovado em: 03/06/2020

Revisado em: 08/09/2020 


\section{Introdução}

Na gestão do Ministro da Saúde José Gomes Temporão (2007-2010), um dos 22 princípios e propostas de governo anunciados em seu discurso de posse foi a instituição de uma Política Nacional de Saúde do Homem. No ano de 2008, a Política Nacional de Atenção Integral à Saúde do Homem (PNAISH) foi divulgada, em sua primeira versão, sob o argumento de que "a saúde é um direito social básico e de cidadania de todos os homens brasileiros" e "que os agravos do sexo masculino constituem verdadeiros problemas de saúde pública” (BRASIL, 2008a, p. 3). Enfatiza-se ainda que o processo de construçáo do documento foi desenvolvido a partir da parceria entre sociedades médicas "juntamente com a participação de outros profissionais da saúde, pesquisadores, acadêmicos, representantes do CONASS e CONASEMS e de entidades civis organizadas que participaram de 5 (cinco) eventos distintos, onde foram traçados consensos" (BRASIL, 2008a, p. 8, grifos nossos).

Dois aspectos chamam a atenção daqueles que se interessam pelo campo de análise de políticas públicas de saúde: 1) o status de prioridade que a saúde do homem assumiu dentre as políticas do Ministério da Saúde (MS) nesse período, considerando a recente estruturação da área técnica de Saúde do Homem (criada entre 2006 e 2007); 2) a indicação de um processo político participativo e consensual envolvendo agentes sociais distintos e, em uma área onde o debate social não é tão expressivo e com divergências importantes no âmbito acadêmico-científico (MARTINS; MALAMUT, 2013; MENDONÇA; ANDRADE, 2010).

Uma revisão preliminar em torno do tema revela que a saúde do homem começou a ganhar espaço na arena acadêmica e política em diferentes países na segunda metade dos anos 1990, com a realização de congressos, fóruns e conferências, com a criaçấo de uma sociedade internacional (1999) e a edição de revistas acadêmicas internacionais The Journal of Men's Studies (desde 1992); International Journal of Men's Health (desde 2003); The Journal of Men's Health \& Gender (desde 2008) (RICHARDSON; CARROLL, 2009; RICHARDSON; SMITH, 2011; TEO et al., 2015). De acordo com esses autores, a Austrália e a Irlanda são países vistos como os pioneiros no mundo no que tange à formulação de políticas de saúde dos homens e se destacam também por terem envolvido parcela da sociedade civil nessa construção.

No Brasil, a temática da saúde do homem ganhou contorno no debate político na década de 2000, tendo importante protagonismo da Sociedade Brasileira de 
Urologia (SBU), que promoveu, desde o início da década, a realização de encontros científicos e campanhas de prevenção para controle do câncer de próstata. O debate acadêmico extrapolou o campo biomédico a partir de 2005, com a edição de um número especial da Revista Ciência \& Saúde Coletiva vinculando o tema a uma discussão inicial de gênero e masculinidades. Em 2009, com a publicação oficial da PNAISH, a temática ganhou ainda maior espaço no debate acadêmico, institucional e social suscitando novas reflexôes, em especial a crítica à perspectiva biomédica que a política reforçava (CARRARA; RUSSO; FARO, 2009; LEAL; FIGUEIREDO; NOGUEIRA-DA-SILVA, 2012).

Nesse contexto, causa estranhamento quando, em seu documento oficial, a PNAISH se apresenta como resultado de consensos, tal como é referido na apresentação do documento em sua primeira versão. A partir da afirmação de participação envolvendo diferentes agentes sociais resultando em um possível consenso, foram elaboradas questóes que mobilizaram o desenvolvimento deste estudo. O que, exatamente, se configurou como consenso nessa política? Como e por que a área de saúde do homem tornou-se prioritária na agenda do Ministério da Saúde a partir de 2007? Quais argumentos foram utilizados para sustentar tal prioridade? Quem foram os agentes sociais que participaram da construção da política e o que demandavam como ação de política pública? Como ocorreu a participação desses agentes? Em que medida houve consenso entre as leituras de saúde do homem propostas pelo campo biomédico e as leituras apresentadas pela perspectiva de gênero e masculinidade, vocalizadas pelos agentes da Saúde Coletiva? O que o modo de construção dessa política nos ensina sobre a formulação de políticas públicas de saúde no Brasil?

Um primeiro passo no desenvolvimento deste estudo foi buscar compreender como os conceitos de Estado, políticas públicas, participação e democracia se apresentaram na construção da política. Procuramos olhar para os processos, mediações e relaçóes que se estabeleceram no debate dessa política a partir das contribuiçóes de autores como Bourdieu (2014), Bowe, Ball e Gold (1992) e Ball (1994), Dean (2016) e Mouffe (2015). Para a compreensão de Estado, campo e agentes sociais, recorremos a Pierre Bourdieu (2004; 2011; 2014), e relacionamos esses conceitos à compreensão proposta por Ball (1994) sobre contextos para produção de políticas públicas.

As contribuiçôes de Bourdieu (2004; 2011; 2014) foram importantes para desprender-nos de um pensamento que temos como natural, em que Estado é tido 
como universal, permitindo-nos distanciar da ideia de Estado como o lugar da neutralidade e da imparcialidade. Em relaçáo ao conceito de campo, este se encontra relacionado ao de agentes sociais e capital (específico de cada campo). Campo, segundo o autor, pode ser entendido como um universo no qual estão inseridos os agentes sociais. Esses agentes podem ser indivíduos ou instituições e são tanto determinados pelo campo, ao qual fazem parte, quanto o estruturam (BOURDIEU, 2004; 2011; 2014). Esse universo possui uma lógica própria, com regras internas que os fazem ser mais ou menos estáveis.

Os campos são também campos de força e de lutas tanto internamente-de maneira a se conservarem ou se transformarem - quanto externamente. Internamente, os agentes sociais se relacionam entre si através de relaçóes objetivas, entendidas como os princípios do campo. Esses princípios determinam a estrutura do campo e são construídos pelos agentes sociais que possuem diferentes pesos de capital específico. Para Bourdieu (2004, p. 26), "cada campo é o lugar de constituição de uma forma específica de capital”. Dessa forma, os agentes sociais ocupam posiçôes distintas e essas posiçóes são definidas, conforme o capital que possuem no campo.

A partir desses conceitos de campo e agentes sociais, os associamos à discussão de política pública, tal como foi formulada por Bowe, Ball e Gold (1992) e Ball (1994). Para esses autores, o desenvolvimento de uma política pública ocorre em diversos cenários ou arenas que, por sua vez, emergem de diferentes contextos, tais como da influência, da produção de texto e da prática. Para eles, a política, ao emergir desses contextos, se expressa como texto e discurso. Iremos nos dedicar, neste estudo, a analisar o que Ball (1994) denomina contexto de influência, referindo-se ao momento em que a política geralmente é iniciada e os discursos construídos a partir de diferentes partes interessadas. Essas partes podem estar em arenas distintas de atuação e lutar entre si para influenciar na definiçãa de uma política específica. Dessa forma, conceitos-chave da política são estabelecidos a partir de disputas entre diversas arenas, públicas ou privadas, que carregam em si diferentes ideologias e valores.

Pensar a política partindo de distintos cenários, que conformam os contextos de influência, da prática e de produção de textos nos quais a política emerge ou acontece, permite pensarmos esses cenários como espaços institucionais ou não. Acreditamos que os cenários são estruturados por agentes sociais e possuem suas 
próprias regras, e por isso o entendimento de cenários pode ser, de certa forma, associado ao conceito de campo. Ou seja, esses cenários compostos por agentes sociais podem corresponder a campos distintos, com seus respectivos agentes sociais. Além disso, podem disputar por um lugar no espaço social.

A partir do diálogo com as obras desses autores, foi possível reconhecer que a ação política de um Estado é resultado de construçôes e dinâmicas históricas que se diferenciam no tempo e espaço, não sendo a política pública algo natural ou universal, mas decorrente das contingências e interaçôes de diferentes agentes sociais, que atuam dentro e fora do aparato governamental, em determinados contextos.

Por fim, discutiremos a forma de participação na construção da PNAISH a partir das tipologias de participação, conforme proposto por Dean (2016). Esse autor afirma que participação pode envolver dimensôes de sociabilidade e negociação. A dimensão sociabilidade leva em consideração que pode haver um conflito ou cooperação no espaço em que acontecem as práticas participativas. Considerar esses aspectos é valorizar as diferentes formas de participaçáo, não a reduzindo somente a algo que perpassa uma cooperação sem levar em conta os conflitos que também podem ocorrer. A dimensão de negociação compreende a participação como prescrita ou negociada. No caso do espaço participativo prescrito, quem participa e sobre o que participa é algo definido em um espaço externo e imposto aos participantes. Ou seja, os organizadores são os responsáveis por definir o objeto da participação, assim como os participantes que se envolverão no processo de tomada de decisão. Nos espaços em que a participaçáo é negociada, os participantes são tidos como parte do processo; logo, eles têm determinada autonomia para negociar quem irá participar, os objetivos da participaçáo e as regras entre os participantes. Neste caso, a participação acontece de maneira horizontal, diferentemente da prescrição em que as relaçôes de poder se expressam verticalmente. Segundo Dean (2016), tanto sociabilidade quanto negociação são dimensóes importantes para pensarmos participação nas decisóes políticas e essas aparecem, de alguma forma, nas teorias sobre democracia e administração pública, influenciando os rumos da participação em diferentes espaços em que ela acontece.

Para análise da política a partir de uma perspectiva democrática, recorremos aos estudos de Laclau e Mouffe (2015) e Mouffe (2015). Os autores advogam que a sociedade é formada por uma pluralidade na qual é possível haver antagonismos, 
sendo o conflito o terreno da própria democracia. Mouffe (2015) acredita que, geralmente, os antagonismos são negados pela perspectiva consensual, já que esta nos faz acreditar que existe a possibilidade de um diálogo e, a partir deste, uma deliberação sobre assuntos correlatos ao bem comum. Essa concepção tende a se sobrepor à ideia de conflito e se sustenta pela ideia de que é possível, a partir do consenso, tomar-se uma decisão. Mouffe (2015) discorda dessa ideia, pois acredita que existe uma dimensão afetiva que faz com que os agentes se identifiquem a determinados grupos e não a outros, e isso permite que os projetos se configurem de maneira diferente. Ou seja, a autora acredita que a diferença entre os grupos é a marca de uma identidade, algo que sugere mais a presença de conflito do que a possibilidade de uma escolha racional visando um consenso.

Partimos da análise sobre as estratégias de participação para discutir o que se configurou como consenso nessa política. Veremos no estudo sobre a PNAISH que a ideia de consenso se tornou um argumento-chave para legitimação da política. Diante disso, o objetivo deste artigo ${ }^{1}$ é colocar em análise o processo de construção da PNAISH, com vistas a reconhecer as estratégias utilizadas pelos diferentes agentes sociais na formulação dessa política pública, problematizando a ideia de participação adotada. Com este estudo, buscamos nos aproximar do entendimento da direcionalidade da política de saúde no Brasil e dos modos de operar a construção de políticas, em especial os mecanismos de participação utilizados, visando potencializar o debate político e democrático em nosso país.

\section{Percurso metodológico}

O período de análise do estudo foi aquele anterior ao lançamento oficial do documento PNAISH pelo MS no ano de 2009. Foi construída uma linha do tempo com a identificação dos principais eventos e acontecimentos que marcaram a trajetória da política (figura 1), bem como análises e produçóes relativas ao tema. Localizou-se o ano de 2000 como o início de ações destinadas à saúde do homem, com as campanhas de prevenção realizadas pela SBU. Como marco inicial de produção de debate sobre saúde do homem no Brasil, identificou-se o período de 2004 a 2009, que se refere às primeiras estratégias adotadas pela SBU e por outros agentes sociais até o lançamento da PNAISH. 
Figura 1. Linha do tempo do processo de construção da PNAISH

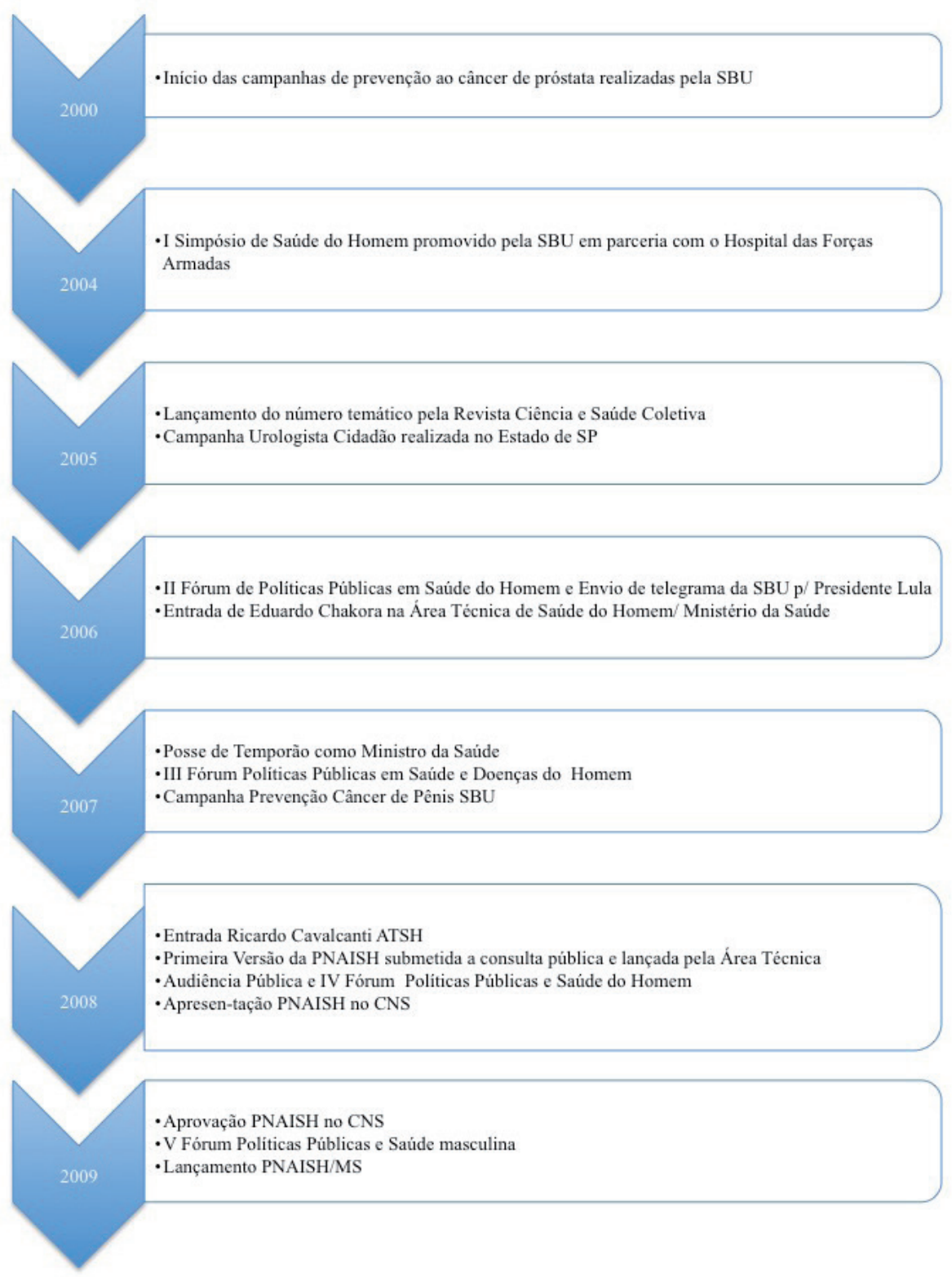

Fonte: Elaborado pelas autoras a partir dos documentos analisados, 2018. 
O estudo foi desenvolvido em dois momentos. O primeiro consistiu no mapeamento e análise de documentos (atas de reunióes e registro de eventos do MS, do Conselho Nacional de Saúde, do Legislativo federal), mídias (encontros, entrevistas, matérias de ONGs, do MS, do Legislativo) e artigos (revisão bibliográfica) com o tema da política de saúde do homem. A partir dessa análise, foi possível um primeiro mapeamento dos diferentes grupos e agentes envolvidos no debate da política (tais como ONGs; acadêmicos, sociedades médicas e parlamentares), bem como a identificação dos argumentos e questôes apresentados por eles. O segundo momento consistiu na realização de entrevistas com parte dos agentes sociais identificados, e ainda outros agentes, incluídos à medida que as entrevistas eram realizadas.

Apesar de reconhecermos que no interior de cada campo há lutas e disputas que não são homogêneas, associamos os agentes sociais a alguns cenários buscando uma aproximação ao conceito de campo, conforme definido por Bourdieu (2004). Consideramos, para fins de apresentação dos resultados do estudo, que os agentes sociais entrevistados refletem parcialmente algumas das regras e formas de relação presentes em cada âmbito, são eles: Ministério da Saúde; Legislativo; acadêmico; sociedades médicas. No quadro 1, estão apontados os cenários investigados, com os respectivos agentes entrevistados e sua inserção no momento da construção da PNAISH.

Quadro 1. Inserção dos agentes sociais entrevistados e atuação no momento do processo de construção da PNAISH

\begin{tabular}{|l|l|l|}
\hline Cenário & Agente Social & Inserçáo \\
\hline Ministério da Saúde & José Gomes Temporão & $\begin{array}{l}\text { Secretário de Atenção à Saúde e, } \\
\text { posteriormente, ministro da saúde }\end{array}$ \\
\cline { 2 - 3 } & Ricardo Cavalcanti & $\begin{array}{l}\text { Primeiro coordenador da Área Técnica de } \\
\text { Saúde do Homem (ATSH) }\end{array}$ \\
\cline { 2 - 3 } & Eduardo Chakora & Primeiro técnico que também compôs a ATSH \\
\cline { 2 - 3 } & Liliane Penello & $\begin{array}{l}\text { Coordenadora da Estratégia Brasileirinhos e } \\
\text { Brasileiras Saudáveis desde 2007 na Fundação } \\
\text { Oswaldo Cruz (Fiocruz) Brasília }\end{array}$ \\
\cline { 2 - 3 } & Maria do Socorro Souza & $\begin{array}{l}\text { Conselheira do Conselho Nacional de Saúde } \\
\text { (CNS) }\end{array}$ \\
\hline
\end{tabular}

continua... 


\begin{tabular}{|c|c|c|}
\hline Cenário & Agente Social & Inserção \\
\hline \multirow[t]{3}{*}{ Acadêmico } & Márcia Couto & Docente da UNIFESP \\
\hline & Romeu Gomes & $\begin{array}{l}\text { Pesquisador do Instituto Fernandes Figueira } \\
\text { (IFF)/ Fiocruz }\end{array}$ \\
\hline & Wagner Figueiredo & Médico do Centro de Saúde Escola da USP \\
\hline Instituto Papai & Benedito Medrado & Colaborador do Instituto PAPAI \\
\hline Promundo & Marcos Nascimento & Primeiro membro da equipe da $\mathrm{ONG}$ \\
\hline ABGLT & Beto de Jesus & Membro da Associação \\
\hline \multirow[t]{3}{*}{$\begin{array}{l}\text { Sociedade Brasileira de } \\
\text { Urologia (SBU) }\end{array}$} & José Carlos de Almeida & $\begin{array}{l}\text { Presidente eleito no período de } 2005 \text { a } 2007 \\
\text { da SBU. Em 2008, entra efetivamente no } \\
\text { cargo de presidente e permanece até } 2009\end{array}$ \\
\hline & Aguinaldo Nardi & Presidente da SBU seccional São Paulo \\
\hline & Sidney Glina & Presidente da SBU entre 2006 e 2007 \\
\hline $\begin{array}{l}\text { Sociedade Brasileira de } \\
\text { Cardiologia (SBC) }\end{array}$ & $\begin{array}{l}\text { Antônio Carlos } \\
\text { Palandri Chagas }\end{array}$ & Presidente da SBC \\
\hline $\begin{array}{l}\text { Sociedade Brasileira de } \\
\text { Medicina de Família e } \\
\text { Comunidade (SBMFC) }\end{array}$ & Gustavo Gusso & Presidente da SBMFC \\
\hline
\end{tabular}

Fonte: elaborado pelas autoras, a partir das entrevistas e consulta aos currículos, 2018.

Por se tratar de uma análise de política pública, cuja seleção dos entrevistados tem a ver com sua atuação no Ministério da Saúde ou papel desempenhado na formulação da política, foi solicitada, por intermédio do Termo de Consentimento Livre e Esclarecido, autorização para identificação das falas, concedida por todos os participantes das entrevistas. O estudo foi aprovado pelo Comitê de Ética (CEP) em Pesquisa da Escola Nacional de Saúde Pública Sérgio Arouca (ENSP) da Fiocruz, sob o Parecer de no 1.413 .443$.

Para proceder à interpretação dos documentos e entrevistas, foram utilizados alguns referenciais. No que se refere a sua organização inicial, tratamento e exploração do material de pesquisa, seguimos as orientaçôes de Minayo (2006), buscando identificar elementos em comum e pontos de afastamento entre os diferentes discursos, definindo categorias iniciais de análise. As entrevistas foram lidas na íntegra, conforme os cenários de cada agente social. Essa leitura permitiu aflorar os sentidos, de forma a náo ficarmos capturadas por categorias a priori. Em 
seguida, a leitura das entrevistas teve como objetivo identificar as categorias teóricas, como relacionadas ao processo de construção da política e ao processo de participação em sua construção, que estão em consonância com as perguntas e objetivos da pesquisa. No entanto, outras categorias, denominadas categorias de análise, foram sendo reconhecidas ao longo de cada entrevista e conforme cada cenário.

É importante ressaltar que, se em um primeiro momento as categorias teóricas foram comuns a todas as entrevistas, as de análise, que surgiram ao longo da leitura de cada entrevista, se diferenciaram. Isso se deve, sobretudo, à posição de cada agente social em cenários e campos distintos. Ou seja, há agentes que se situavam no Ministério da Saúde e que apontavam para o percurso da política no interior desse cenário. Neste caso, "percurso da política no MS" se tornou uma categoria de análise. Por outro lado, outros agentes, como aqueles que estavam abordando o processo a partir da sua experiência nas ONGs ou em instituiçóes de pesquisa ou de ensino, ofereceram elementos para o surgimento de outras categorias, como "efeitos da política".

Em um segundo momento, procedeu-se à interpretação e compreensão dos discursos, em especial das entrevistas, a partir da construção de um mapa de associação de ideias, conforme proposto por Spink (2013). O mapa consistiu na categorização de cada entrevista considerando os temas elencados na organização inicial do estudo, o cenário de inserção de cada entrevistado e a relação do entrevistado com os demais cenários e agentes. $\mathrm{O}$ resultado da análise permitiu estabelecer um cruzamento entre agentes e ideias e o entendimento sobre como os diferentes agentes sociais atuaram no processo de construção da política a partir das categorias de cada entrevistado. Com isso, foi possível reunir uma compreensão abrangente sobre o modo de construção dessa política pública com ensinamentos para pensar as características do processo político no Brasil.

\section{Os caminhos de construção da PNAISH}

Neste tópico, abordaremos os principais agentes envolvidos no processo de construção da PNAISH. Em um primeiro momento, são destacadas as açōes e iniciativas promovidas pela SBU, seguindo das açóes da academia e do MS.

Os primeiros movimentos com vistas à elaboração de uma ação política relativa à saúde do homem surgem no início dos anos 2000 com as campanhas de prevenção do 
câncer de próstata promovidas pela SBU. No ano de 2004, a SBU realiza o I Simpósio de Saúde do Homem em parceria com o Hospital das Forças Armadas (HFA) (figura 1 - linha do tempo) e, com isso, plantava a semente da saúde do homem no Brasil, conforme relato do entâo presidente da SBU, José Carlos de Almeida, que destaca como objetivo do Simpósio dar visibilidade à especialidade da urologia, considerada escondida e estigmatizada. A partir de 2005, foram realizados com periodicidade anual, no âmbito da Câmara dos Deputados (CD), os Fóruns de Saúde do Homem. Nesses fóruns, o Ministério da Saúde, o Instituto Nacional do Câncer (INCA), o HFA, além de deputados e senadores e outras especialidades médicas, como a cardiologia, foram convidados a debater sobre doenças que acometiam os homens. ${ }^{2}$ Ao analisarmos a programação dos fóruns, foi possível perceber a centralidade do debate nas doenças urológicas. A partir do III Fórum (2007) outros temas foram considerados, como as doenças sexualmente transmissíveis (DST) e a violência, buscando também o diálogo com outros interlocutores, como representantes de ONGs atuantes no campo.

Os fóruns foram promovidos pela Comissão de Seguridade Social e Família (CSSF) e pela Frente Parlamentar da Saúde (FPS) da CD, mas foram conduzidos pelo presidente da SBU, revelando uma atuaçáo importante da sociedade médica no cenário Legislativo, explicitando um modo de atuação da corporação médica no processo político brasileiro com articulação de interesses e pressão política via Legislativo e Executivo. Conforme Baptista, Gomes e Nogueira (2012), no Governo Lula, dentre os inúmeros projetos de lei referentes à saúde, o Legislativo promoveu audiências públicas e seminários temáticos - dentre esses, Fóruns de Políticas Públicas de Saúde do Homem - contando com convidados externos, especialistas e representantes do governo e de diferentes movimentos sociais.

Enquanto os fóruns e as demais açóes promovidas pela SBU junto ao Legislativo ocorriam no período de 2000 a 2007, o cenário acadêmico também parecia já vir se preparando para pesquisar, refletir e apontar propostas para o tema saúde do homem. O ano de 2005 merece destaque com a publicação de um número da Revista Ciência \& Saúde Coletiva, uma das principais do campo da Saúde Coletiva, dedicado ao tema "Saúde do Homem: alerta e relevância" (CIÊNCIA \& SAÚDE COLETIVA, 2005). A revista teve como editores convidados os pesquisadores Romeu Gomes, Lilia Schraiber e Márcia Thereza Couto, referências importantes da Saúde Coletiva. O editorial intitulado "O homem como foco da Saúde Pública" e o artigo para 
debate "Homens e saúde na pauta da Saúde Coletiva", ambos escritos pelos editores convidados, provocava o debate no sentido de ampliar a abordagem do tema para além do enfoque biomédico relacionando à discussão sobre gênero e saúde, o que é enunciado como uma intenção de "ressignificação do masculino" e problematização sobre masculinidade hegemônica (GOMES; SCHRAIBER; COUTO, 2005, p. 4). Os artigos de debate e demais artigos produzidos no número têm como foco a ideia de que é importante pensar a relação homens e saúde levando em consideração as diferenças entre eles próprios, e entre eles e outros sujeitos da sociedade. Na discussão sobre as causas de morbimortalidade, os artigos tendem a enfatizar a violência e outras causas externas prevalentes nesse público.

Conforme entrevista realizada com Márcia Couto, esta recebeu o convite de Cecília Minayo, em 2003, para atuar junto a Romeu Gomes e Lília Schraiber como editores do número especial da Revista, cujo enfoque deveria ser a saúde do homem. A partir desse número, segundo informa, foram lançados editais de pesquisa do Conselho Nacional de Desenvolvimento Científico e Tecnológico (CNPq) envolvendo dentre outros assuntos, a saúde da população masculina. Isso nos mostra que havia um interesse de agentes do Estado para que o tema fosse trabalhado também no âmbito acadêmico. Assim, a produção dessa revista mostra a entrada do tema na área com a delimitação de questôes que são indicativas de disputa com o discurso hegemônico da biomedicina e que estarão presentes em todo o processo de construção da política.

No cenário institucional do MS, a política de saúde do homem começa a ganhar contornos entre os anos de 2006 e 2007, quando o então secretário de Atenção à Saúde, José Gomes Temporão, propóe a criação da Área Técnica de Saúde do Homem (ATSH). Assim, em 2006, estabelece-se um projeto com a contratação, via Organização Panamericana da Saúde (OPAS), do técnico Eduardo Chakora, psicólogo clínico com experiência em grupos de homens, designado para a tarefa de: "mapear as diversas instituiçóes do país, públicas ou privadas, que desenvolviam açóes de saúde dirigidas à população masculina; [...] e realizar um levantamento da produção bibliográfica em saúde da população masculina"3. A área técnica ainda não existia propriamente e a consultoria surgia como um primeiro passo na construção de uma futura saúde do homem, uma estratégia planejada para desenvolvimento da área, conforme relato de Chakora. 
Ressalte-se que a nomeação de um técnico, sem experiência prévia com Saúde Coletiva e sem formação médica, para realização de estudos relativos à saúde da população masculina parece ter sido uma estratégia do secretário de Atenção à Saúde para garantir uma ampliação do olhar sobre a atenção à saúde do homem. Segundo alguns entrevistados, o perfil de quem deveria atuar na ATSH foi definido com recomendaçôes do secretário que entendia a necessidade de a área se constituir com um profissional médico que pudesse manter a interlocução com as sociedades médicas, especialmente com a SBU, e alguém que pudesse equilibrar o peso das sociedades médicas, a partir de um olhar da Saúde Coletiva, intenção também relatada no estudo de Müller e Birman (2016). Assim, nesse primeiro momento, a área constitui-se com um representante do segundo segmento, trazendo as contribuições de outros campos de conhecimento que não o biomédico. A partir do posicionamento do ministro Temporão em tentar equilibrar o peso da SBU, é possível afirmar que houve o entendimento, desde o início, de que havia ali pelo menos duas perspectivas sobre como lidar com a saúde do homem.

Mas também nesse período é possível reconhecer a forte atuação da SBU junto ao MS, indicando a necessidade da política. Segundo o então presidente da SBU, em 2006 foi enviado um telegrama ao presidente Lula para que pudesse realizar uma audiência com a SBU sobre assuntos relacionados à saúde masculina. A audiência não ocorreu, mas ainda segundo José Carlos de Almeida, a assessoria do presidente da República, encaminhou uma resposta ao telegrama afirmando que a solicitação seria atendida e que, para isso, seria encaminhada ao Ministério da Saúde uma demanda visando estudar a possibilidade de criação de uma coordenação de saúde do homem. Esse relato sugere que a criação da ATSH e a indicação de Eduardo Chakora como um representante da Saúde Coletiva foi uma estratégia utilizada pelo então secretário do MS na mediação dos interesses que envolviam Presidência da República, SBU e MS.

No ano de 2007, o secretário de Atenção à Saúde é nomeado Ministro da Saúde e a área de Saúde do Homem assume status de prioridade na agenda do ministro, que a enuncia no discurso de posse entre os 22 princípios e propostas do governo (TEMPORÃO, 2007).

A prioridade anunciada deve ser compreendida no contexto em que se insere. Considerando outras áreas e açóes do MS, a saúde do homem ganha um reforço nesse período, mas não se compara a outras áreas em termos de investimento e ações. 
Contudo, ganha um acompanhamento interessado por parte do ministro, que já havia orientado, desde 2006, a constituição de uma área de forma a se criar um diálogo entre as sociedades médicas e a Saúde Coletiva. Ou seja, há uma mediação entre os interesses da SBU e os interesses da Saúde Coletiva, que possui um discurso de abordar o homem a partir de uma perspectiva ampla, com foco na promoção da saúde e de forma articulada com a Política de Atenção Básica, conforme Eduardo Chakora.

Nesse sentido, os argumentos utilizados para sustentar a prioridade da nova política também estiveram vinculados muito mais a questóes gerais que afetam a saúde do homem, como agravos diversos relacionados a violência e situaçôes de alcoolismo e tabagismo, e outros relacionados às doenças crônicas, mais do que necessariamente a neoplasias, como o câncer de próstata, um problema de menor magnitude no cenário epidemiológico.

A partir de 2007, a ATSH ganha nova configuração e uma nova equipe passa a constitui-la. Assume, nesse ano, como coordenadora, Neidil Espíndola da Costa, médica, gerontóloga e especialista em Saúde Pública, que permaneceu por curto período de tempo, sendo logo substituída por outro médico, Ricardo Cavalcanti, ginecologista e com formação em antropologia. Cavalcanti foi convidado pelo assessor do Ministro e convidou Baldur Schubert, médico e especialista em Saúde Pública, para atuar como seu assessor. Com a saída de Cavalcanti após alguns meses como coordenador, Baldur assume a coordenação da ATSH.

$\mathrm{Ou}$ seja, a constituiçáo propriamente dita da ATSH incorporou, direta e indiretamente, desde seu início, o segmento médico na sua condução. Apesar da atuação de Eduardo Chakora no estudo do tema, desde os primórdios de configuração da área, foi um médico que assumiu a coordenação da área no momento de definição da política. Chakora manteve-se na equipe prestando consultoria. A orientação dada por Temporão, ainda como secretário, de manter em diálogo dois olhares - médico e da Saúde Coletiva - para a saúde do homem se confirma nessa configuração da área, mas o peso da medicina está expresso também em sua configuração.

É importante ressaltar também que, em 2008, segundo José Carlos de Almeida, a SBU organiza um dossiê, que foi entregue diretamente ao então ministro da saúde, José Gomes Temporão. Nesse dossiê, os problemas urológicos - câncer de próstata, disfunção erétil e sexual e câncer de pênis - mais frequentes na população masculina são relatados. Nesse ano, estava em fase de finalização uma primeira 
versão do texto da política sendo o dossiê mais um documento a compor o rol de contribuiçôes ao processo político.

A partir de 2007, a ATSH inicia a mobilização para a construção do documento da política e alcança em 2008 uma primeira versão para consulta pública. Esta consistiu de comentários e sugestóes e teve como objetivo ampliar a participação de sociedades científicas, academia e sociedade civil que porventura não haviam participado do seu processo de elaboraçáo, mas que tinham interesse em contribuir com o texto da política (BRASIL, 2008b). Após essa consulta pública, tanto Ricardo Cavalcanti quanto Eduardo Chakora ficaram responsáveis pela consolidaçáo das sugestóes, conforme Chakora. Em 2009, o documento chega a sua versão final, quando então é publicada e divulgada oficialmente. A análise da participação dos diferentes agentes na construção dessa política é importante para compreensão do processo político, revelando as disputas e tensionamentos em torno do projeto de atenção à saúde que se desejava imprimir naquele momento.

\section{A participação dos agentes sociais no processo de construção da PNAISH}

O processo político na construção do documento foi organizado e liderado pela ATSH iniciando com um levantamento, através dos sistemas de informação do MS, das principais causas de morbimortalidade da população masculina, compreendida em determinada faixa etária - 20 a 59 anos. O levantamento revelou que as principais causas de adoecimento e morte da população masculina estavam relacionadas com as masculinidades. Diferentemente do que advogava a SBU, as neoplasias não se apresentavam como principal causa de morte ou de adoecimento, sendo muito mais importantes as causas externas, em especial as decorrentes da violência e doenças cardiovasculares.

Assim, uma primeira disputa na orientação estratégica da política decorre da interpretação dos dados epidemiológicos e a definição de prioridades de ação. $\mathrm{Na}$ leitura do coordenador Ricardo Cavalcanti, mesmo as causas externas sendo uma importante causa de morbimortalidade, o MS não teria como atuar de forma efetiva no seu controle, pois elas referem-se a questôes estruturais que fogem ao escopo de atuação da saúde, devendo o MS dedicar-se, naquele momento, a açôes que seriam mais efetivas no controle das doenças, como o controle do câncer de próstata e das doenças 
cardiovasculares. Já para Eduardo Chakora, a importância das causas externas não deveria ser desprezada e exigiria a interlocução com a área de Saúde Mental e outros setores do governo. Caberia, dessa forma, ao MS definir uma política que pudesse abarcar açōes de natureza diferentes, mobilizando outros setores e agentes sociais.

O debate inicial em torno do levantamento epidemiológico suscitou a necessidade de ampliação do diálogo com outros agentes, o que levou a uma agenda de seminários com o objetivo de ouvir especialistas e promover um processo de construção da política de baixo para cima, conforme relato de Ricardo Cavalcanti.

A escuta de especialistas tinha um duplo objetivo: reconhecer como as diferentes especialidades entendiam o perfil de morbimortalidade dos homens e identificar o que julgavam ser as dificuldades dos homens para frequentar os serviços de saúde e realizar açóes de prevençáo. Desse modo, a estratégia de promover a participação tinha como foco central absorver o conhecimento dos especialistas para definir um projeto de ação política. A ideia central tanto do coordenador Ricardo Cavalcanti como do técnico Eduardo Chakora era trazer outros agentes, que não apenas os gestores do MS, para o debate e construção da política. Ressalte-se que esse modelo de participação reforça um modo de atuação que não necessariamente convida ao diálogo e à construção coletiva, mas valoriza a transferência de conhecimento do especialista para um agente de maior poder, que definirá a ação, no caso o gestor do MS.

O convite à participação nos seminários revela um pouco mais do modo de operar a construção dessa política. Alguns agentes sociais foram reconhecidos pelo coordenador, médico, e outros pelo técnico, psicólogo, Eduardo Chakora. Para o coordenador, a opinião e experiência de especialistas médicos, em especial urologistas e cardiologistas, de diferentes regióes do país eram necessárias para ampliação do conhecimento dos gestores na construção do documento. Já para Chakora, a participação nos seminários não deveria restringir-se à categoria médica ou ao foco na doença, mas incluir outros grupos e instituiçóes que tivessem uma abordagem mais ampla e comprometida com a perspectiva biopsicossocial.

Cavalcanti partia do reconhecimento de agentes vinculados às sociedades médicas e seus interlocutores no campo médico, considerando inclusive sua atuação como profissional de saúde. Chakora partia do mapeamento de referências acadêmicas e grupos atuantes no debate sobre saúde do homem para propor a participação de novos agentes, buscando ampliar a visão da política e valorizar a perspectiva da integralidade do cuidado. Foi nesse contexto que reconheceu a importância da 
aproximação com a Sociedade Brasileira de Medicina de Família e Comunidade (SBMFC), das ONGs Promundo e Instituto Papai, da Associação Brasileira de Gays, Lésbicas, Bissexuais, Travestis e Transexuais (ABGLT) e de acadêmicos. A SBMFC mostrava-se importante para garantir a incorporação da política no âmbito da Atenção Básica; já as ONGs identificadas, conforme Chakora, tinham um trabalho mais consolidado, mais sólido com a questão dos homens e das mulheres, trazendo questôes pertinentes às demandas dos homens. Os pesquisadores, como Marcia Thereza Couto e Romeu Gomes, traziam o debate sobre masculinidades e estudos como uma leitura critica sobre a frequência de homens em serviços de saúde.

Nesse sentido, é interessante perceber o esforço de Chakora na interlocução e mediação do processo, o que na avaliação de alguns entrevistados funcionou como um contrapeso, para garantir que não fosse só um grupo o vencedor, ou seja, o olhar médico.

Mas a participação dos diferentes agentes também ocorreu com padrôes diferenciados, sem uma interação mais efetiva entre os grupos, com a mediação realizada pelos gestores da ATSH e cada grupo de convidados. Os seminários foram organizados conforme as especialidades médicas, sendo apenas o Seminário de Saúde Mental realizado com a participação de agentes não médicos.

O Seminário de Saúde Mental foi o primeiro a ocorrer e teve como objetivo tratar da discussão sobre as causas externas. Foi designado como de Saúde Mental por abarcar temas como: álcool, drogas, violência, pulsôes de morte, além das questôes socioculturais. Ocorreu durante dois dias e reuniu um conjunto diversificado de agentes, como ONGs (Instituto Papai, Promundo), associações médicas (Associação Brasileira de Psiquiatria - ABP), pesquisadores e ativistas sociais (ABGLT). Os convidados foram divididos em quatro subgrupos, assim definidos: Adesão a Programas de Saúde; Agressóes; Suicídios; Acidentes de Transportes. A orientação foi de compor grupos com representaçôes distintas, de modo a intensificar o debate.

A estratégia de aproximação entre os grupos parece não ter funcionado. Conforme relato de um representante da academia, Wagner Figueiredo, a discussão ficou polarizada em dois posicionamentos, um mais próximo do entendimento médico, ali representada pela $\mathrm{ABP}$, com uma postura mais pragmática pensando nas doenças ou nos problemas e quais açôes poderiam ser desenvolvidas; e outro abarcando os outros - sociedade civil, ONGS e pesquisadores - vocalizando uma perspectiva de gênero e da socioantropologia. 
Depois do primeiro Seminário de Saúde Mental, seguiu-se a realização dos seminários com as sociedades médicas, com a SBU, abordando temas como: hiperplasia prostática benigna, câncer de próstata e de pênis, planejamento familiar masculino e medicina sexual; seguido dos seminários com a Sociedade Brasileira de Cardiologia, com a Federação Brasileira de Gastroenterologia e com a Sociedade de Pneumologia e Tisiologia. Conforme relato dos representantes das sociedades médicas, Antônio Carlos Palandri Chagas, Sidney Glina e Aguinaldo Nardi, as sociedades se viram como consultores para a construção do documento PNAISH. A consultoria consistia em apresentar e debater temas das especialidades a partir de grupos de estudos.

Outro seminário realizado foi com a Sociedade Brasileira de Medicina de Família e Comunidade (SBMFC). Ocorreu no meio da discussão da política e foi definido a partir de um reconhecimento posterior da necessidade de inclusão deste grupo. Conforme Chakora, a SBMFC não estava incluída inicialmente, mas sua presença se mostrou necessária para ampliar a abordagem da política, evitando a redução do homem à próstata, ao coração e às especialidades médicas, aproximando o tema da política de Atenção Básica à Saúde. Conforme o representante da SBMFC, Gustavo Gusso, a sociedade náo apresentava uma agenda própria como as demais, mas buscou contribuir para o debate da política a partir do que reconhecia como as demandas das pessoas.

Para cada seminário foram previstos 55 participantes, assim divididos: 27 presidentes estaduais das sociedades médicas; cinco membros da diretoria dessas Sociedades; sete representantes de universidades; seis representantes do Conselho Nacional de Secretários de Saúde (CONASS) e do Conselho Nacional de Secretarias Municipais de Saúde (CONASEMS); 10 representantes de áreas do Ministério da Saúde, como Secretaria Executiva (SE), Secretaria de Vigilância à Saúde (SVS), Secretaria de Gestão Estratégica e Participativa (SGEP), Secretaria de Gestão do Trabalho e da Educação na Saúde (SGTES), Departamento de Ações Programáticas Estratégicas (DAPES), Departamento de Atenção Básica (DAB), Departamento de Atenção Especializada e Temática (DAET), Departamento de Regulação, Avaliação e Controle de Sistemas (DRAC) e Instituto Nacional do Câncer (INCA). ${ }^{4}$ Dessa forma, foi feito um esforço interno e externo para aproximação e convencimento da importância da política entre diferentes segmentos e áreas relacionadas ao MS. 
Após os insumos obtidos nos seminários, a equipe da ATSH debruçou-se na construção de uma versão final do texto da política. Seguindo a orientação de ampliação do debate, o documento foi submetido em setembro de 2008 a consulta Ppblica por 30 dias, com as contribuiçốes mediadas pela ATSH para elaboração do texto final. Enfim, o documento passou pelo Conselho Nacional de Saúde (CNS) e pela Comissão Intergestores Tripartite (CIT), sendo lançado em 2009, seguindo, conforme José Gomes Temporão, os trâmites do processo de formulação de uma política.

Neste ponto, é fundamental perceber que havia todo um percurso que a política deveria seguir, como passar por comissóes e órgáos do Estado para receber o selo oficial, uma forma de garantir a legitimidade da política. O documento PNAISH foi apresentado pela primeira vez no CNS em outubro de 2008, e em julho de 2009 a ATSH fez uma nova apresentação da versão final da política. Nesse momento, alguns dos conselheiros ali presentes, representando o fórum dos usuários e a população negra, se manifestaram indagando com quem a política havia sido debatida, questionando sobre o foco restrito na doença, além de demonstrarem uma lacuna quanto à presença de populaçôes vulneráveis que deveriam ser priorizadas. Como crítica, ressaltaram que a construção da política deveria ter passado por um processo de discussão mais aprofundado. Apesar das críticas, aqueles que estavam apresentando o documento em nome do MS ao CNS acreditavam que os mecanismos pelos quais a PNAISH havia passado foram suficientes para garantir a participação.

\section{Sobre consensos e conflitos na construção da PNAISH}

A análise dos posicionamentos dos diferentes agentes sociais envolvidos no debate da PNAISH náo indicou exatamente a existência de um consenso, tal como foi mencionado no texto da primeira versão da política. No entanto, há o discurso oficial de que o processo de construção da PNAISH foi pautado em consensos de ideias. Afinal, o que se configurou como consenso nessa política? Alguns aspectos relatados até aqui merecem ser aprofundados.

Foi nítido o esforço realizado pela ATSH em ampliar o debate e considerar a contribuição de diferentes agentes sociais, que não apenas médicos, na construção da política. Contudo, houve um desequilíbrio na participação dos agentes, com maior espaço para atuaçáo das sociedades médicas, presentes em quatro dos cinco seminários realizados. Isso pode ser entendido pelo peso dentro da própria ATSH no 
MS, já que os primeiros coordenadores tinham formação médica. Ressalte-se ainda a atuação das sociedades médicas de forma direta no Executivo e no Legislativo federal, com mecanismos de pressão para o desenvolvimento de política e campanhas de saúde para o homem.

Também a forma de organização do debate não favoreceu o diálogo e confronto de propostas entre os convidados que participaram, pois os encontros foram realizados como seminários temáticos segmentados por especialidades médicas. Apenas o Seminário de Saúde Mental não se restringiu à especialidade médica da psiquiatria e contou com a participação de diferentes agentes. Cada segmento acabou por atuar como consultor do Ministério da Saúde expondo suas questôes e validando as propostas apresentadas pela gestão. Esse formato de participação remete à análise proposta por Dean (2016) sobre os tipos de participação possíveis. Segundo o autor, esta é uma participação entendida como transferência de conhecimento, porque parte do princípio de que há aqueles que decidem a agenda e o formato de um processo político e aqueles que participam como convidados, havendo uma distinção entre quem governa e quem é governado. Nesse tipo de participação, é possível perceber que a transferência de conhecimento acontece pela consulta a um público de especialistas como forma de se conhecer as necessidades e preferências das pessoas que são alvo de uma dada política. A crença é que um elevado grau de conhecimento técnico garante o conhecimento sobre os caminhos para se obter os melhores resultados, desconsiderando a importância que tem a própria população na construção de suas demandas.

Esse formato de participação favoreceu a definição de uma política que atendia aos interesses do grupo majoritário, as sociedades médicas, e enfraqueceu a tentativa de condução de alguns dos agentes do MS na definição de uma política condizente com os interesses do SUS, que aponta o direito à participação social como uma estratégia para melhorar resultados. Assim, por trás do discurso anunciado no texto oficial da política de que se tratou de consensos de ideias democraticamente debatidas (BRASIL, 2008), reconhecemos diferentes conflitos entre os agentes que ali estavam representando racionalidades aparentemente distintas e em disputa por uma saúde do homem. Esse aspecto possui relação tanto com os campos aos quais cada grupo de agentes sociais se vinculavam, quanto conformam um contexto de influência para a definição da política. 
Foi possível perceber uma disputa de entendimentos em torno do processo saúdedoença-cuidado. Dois posicionamentos se apresentaram muito enfaticamente nos discursos dos agentes.

Um discurso, no qual estavam, em geral, os representantes das sociedades e associações médicas, que enunciavam o caráter técnico biomédico da prestação do cuidado em saúde. A principal defesa era a definição de ações no combate a doenças específicas e a organização de serviços próprios para homens, conforme as especialidades médicas. Dentre as principais doenças a serem combatidas, estavam o câncer de próstata e as doenças cardiovasculares, ou seja, urologia e cardiologia, respectivamente. Apesar de configurarem como causas importantes no quadro de morbimortalidade masculina, as causas externas não se enquadraram no discurso das especialidades médicas no rol de ações da saúde, por extrapolarem a especificidade do campo de atuação da saúde.

Outro conjunto de enunciados remetia a uma perspectiva voltada à promoção da saúde do homem, a aspectos socioculturais e a gênero. Nesse grupo havia grande variação de posicionamentos e divergências. Vocalizaram esta perspectiva acadêmicos, ONGs, ativistas e também a SBMFC. Em geral, indicavam a necessidade de uma política com ênfase na Atenção Primária à Saúde e na organização do SUS.

Essa polarização das leituras coloca de um lado as sociedades médicas, em especial a SBU, pelo foco nas ações de combate ao câncer de próstata, e de outro os demais agentes que traziam as causas externas, gênero, masculinidade e aspectos sociais como principais problemas a serem enfrentados.

No entanto, as discordâncias não se resumiam a essas duas leituras. Entre as sociedades médicas havia diferença de ênfase e de entendimentos. A SBMFC, por exemplo, mostrou-se muito mais próxima de uma leitura mais abrangente da saúde do homem do que as demais sociedades. E agentes sociais representando a ABGLT expressaram o descontentamento com os rumos propostos para a política, por reforçar uma leitura de homem que se mantinha restrita ao binômio masculinofeminino, sendo pensada para um tipo específico de homem: os heterossexuais.

Desse modo, não se trata de termos uma visão homogênea entre os grupos, pois é possível perceber que os grupos se formaram na defesa de ideias que passam por um aspecto mais geral, tal como aqueles que defendiam o mercado da saúde para médicos especialistas, sobretudo, urologia e cardiologia; e outro que defendia ampliar o entendimento das necessidades dos homens para então poder se pensar 
nos serviços que deveriam ser oferecidos. Percebemos constantes disputas interna e externamente aos grupos, sobretudo quando vemos que aquele que defendia olhar de forma integral para o homem excluiu o olhar para o homem transexual.

Diante disso, podemos pensar que para a construção da PNAISH não houve exatamente um consenso, mas um antagonismo de ideias. Retomando as contribuiçôes de Mouffe (2015), não se trata necessariamente de uma inimizade; tampouco podemos afirmar que os interesses e a defesa de cada grupo foram reconhecidos como legítimos por ambas as partes. Enquanto parte dos agentes reconhecem que as sociedades médicas atuaram de maneira marcante e importante, tal reconhecimento não pareceu ser recíproco. Houve apagamentos no discurso dos médicos das diferentes contribuiçóes e conflitos que emergiam dos espaços de discussão. $\mathrm{O}$ próprio arranjo de participação proposto pelos gestores não permitiu que os agentes sociais tivessem uma interlocução e conhecimento de quem estava ali participando da construção da política.

O que se chamou de consenso na construçáo dessa política parece ter sido a mediação e conciliação de propostas feitas, posteriormente aos seminários, pelos gestores da ATSH. Coube aos gestores a mediação do conflito e a escolha por uma direcionalidade.

\section{Considerações finais}

A política de saúde do homem nasce como intenção da SBU, desde o início da década de 2000. O MS responde à expectativa da SBU buscando a mediação a partir de uma leitura mais abrangente de saúde, buscando interlocutores na Saúde Coletiva e áreas afins, aproximando o tema do debate de gênero e masculinidade.

A partir de 2008, outros agentes são convidados a participar do processo político propriamente dito - ONGs, acadêmicos, sociedades médicas de Cardiologia, de Medicina de Família e Comunidade, dentre outras - e passam a incorporar outros temas e interesses à política. Contudo, a pauta focada no homem como masculino, portador de genitália, que se mantém distante do serviço de saúde, em especial dos urologistas, é ainda central.

A partir deste estudo, pudemos tomar por referência o Ministério da Saúde, conhecido por propor ou lançar diversas políticas de saúde e o responsável por ter lançado a PNAISH em 2009. Ao invés de olhar para o MS como um sujeito 
homogêneo que produz políticas para a sociedade brasileira pensando na melhoria de sua saúde, optamos por compreendê-lo como órgão oficial de Estado - um lócus privilegiado de construção, articulação e divulgação das políticas nacionais - formado por diversos grupos e influenciado por outros tantos, todos dotados de interesses ora privados, ora coletivos. Contudo, ressalvamos que a ideia de privado não se relaciona a um indivíduo apenas, mas a um grupo de agentes sociais que possui interesses particulares.

Foi importante reconhecer a trajetória da política, desde seu início, para perceber como os processos políticos de tomada de decisão ocorrem e refletem a construção de um documento de política. No caso da PNAISH, duas pessoas foram indicadas para fazer a mediação entre os dois lados: Ricardo Cavalcanti - com formação médica, que o permite fazer interlocução com as sociedades médicas - e Eduardo Chakora - na interlocução com a academia e ONGs. É como se médicos só falassem com médicos e os demais falassem com o interlocutor reconhecido por esses, no caso um psicólogo. Uma indicação que parecia perfeita para ampliar diálogos, mas que não foi o suficiente para incluir outras posições como a da ABGLT.

Considerando o enunciado oficial da política, destaca-se o processo democrático e pactuado na elaboração do documento. Contudo, como exposto, nos bastidores do processo houve conflitos e divergências e os participantes não foram encorajados a se relacionarem entre si para exporem e confrontarem suas diferentes ideias e posicionamentos. A condução do processo, ao tentar buscar um consenso, produziu o apagamento das diferenças e identidades. Um conflito importante expressou-se na polarização de posicionamentos, um que expressava a racionalidade biomédica e outro que se aproximava da perspectiva da Saúde Coletiva. A racionalidade biomédica mostrou toda sua força argumentativa e discursiva, pois além de estar presente entre seus representantes médicos também se fez presente no discurso dos demais agentes, que concordaram não ser possível se furtar a discutir doenças e agravos epidemiológicos.

No processo de construção da política a participação ocorreu de forma fragmentada, sem diálogo ou troca, com afastamento de seus agentes entre si. Isso porque, em 2009, quando a política foi finalmente editada, apresentada como texto, o resultado da negociação foram discursos contraditórios e híbridos sobre a saúde do homem. Um texto com ênfase em determinado tipo de homem, os heterossexuais, afastando outras possibilidades de leitura do homem, como os transsexuais, 
homossexuais, dentre outros. No entanto, apesar da força do discurso médico, outras vozes foram possíveis, ainda que com participação limitada e precária. Parece que a tentativa da Política Nacional de Saúde do Homem foi tentar mediar diferentes visôes, com pequenas concessóes, mas longe de romper com a supremacia do saber biomédico e com todos os seus interesses.

Acreditamos que este estudo apresenta algumas limitaçóes, ao não aprofundar análises que seriam importantes, tais como o processo de construção do número temático da Revista Ciência \& Saúde Coletiva e também os processos de discussão do Conselho Nacional de Saúde e da consulta pública. No entanto, o estudo traz contribuiçôes importantes para a Saúde Coletiva e a análise de políticas de saúde, tanto na perspectiva de registrar e sistematizar um processo institucional, quanto do ponto de vista da reflexão sobre a construção do discurso oficial que se forma em torno das políticas. Há discursos oficiais sobre diversos temas, dentre eles, a própria participação social, mas a compreensão desses processos políticos de construção discursiva nem sempre está presente nas análises das políticas de saúde. Isso anuncia a possibilidade de adotarmos outro olhar sobre esse campo, que tem nos interessado. Acreditamos que, apesar de termos focalizado a análise da participação na construção do documento da Política Nacional de Saúde do Homem, é possível extrapolar o caso aqui estudado para que pensemos como estão sendo construídas outras políticas anunciadas pelo Ministério da Saúde. ${ }^{6}$

\section{Agradecimentos}

Agradecemos a CAPES - por meio do Programa de Excelência Acadêmica (PROEX) Edital 2016/2017 do Programa de Pós-Graduação em Saúde Pública da Escola Nacional de Saúde Pública Sérgio Arouca (Ensp)/ Fiocruz e do Programa de Doutorado Sanduíche no Exterior - e ao CNPq - por meio da concessão de bolsa de doutorado no âmbito do Programa de Pós-Graduação em Saúde Pública da Escola Nacional de Saúde Pública Sérgio Arouca (Ensp)/ Fiocruz e do auxílio financeiro pelo Edital Universal 01/2016 CNPq - pelo financiamento da pesquisa.

\section{Referências}

BALL, S. J. What is policy? Texts, trajectories and toolboxes. In: BALL, S. J. Education Reform: a critical and post-structural approach. London: Open University Press, 1994. p. 14-27. 
BAPTISTA, T. W. F.; GOMES, M. M. G; NOGUEIRA, C. O. O Legislativo e a Saúde: o debate no período do Governo Lula. In: MACHADO, C.; BAPTISTA, T.W.F.; LIMA, L. D. (Org.). Políticas de saúde no Brasil: continuidades e mudanças. Rio de Janeiro: Editora Fiocruz, 2012. p. 283-320.

BOURDIEU, P. Os usos sociais da ciência: por uma sociologia clínica do campo científico. Tradução de Denice Barbara Catani. São Paulo: Editora UNESP, 2004. 86p.

BOURDIEU, P. Razóes práticas. Tradução de Mariza Corrêa. Campinas: Papirus, 2011. 224p.

BOURDIEU, P. Sobre o Estado: Cursos no Collège de France (1989-92). Tradução de Rosa Freire d'Aguiar. São Paulo: Companhia das Letras, 2014. 573p.

BOWE, R.; BALL, S. J.; GOLD, A. The policy process and the process of policy. In: BALL, S. J.; BOWE, R.; GOLD, A. (Eds.). Reforming education \& changing schools: case studies in policy sociology. London: Routledge, 1992. p. $06-23$.

BRASIL. Ministério da Saúde. Secretaria de Atenção à Saúde. Departamento de Açóes Programáticas Estratégicas. Politica Nacional de Atenção Integral à Saúde do Homem: princípios e diretrizes. Brasília: Ministério da Saúde, 2009.

Ministério da Saúde. Secretaria de Atenção à Saúde. Departamento de Açóes Programáticas Estratégicas. Política Nacional de Atenção Integral à Saúde do Homem: princípios e diretrizes. Brasília: Ministério da Saúde, 2008a.

- Ministério da Saúde. Secretaria de Atenção à Saúde. Departamento de Açôes Programáticas Estratégicas. Consulta Pública do Sistema Único de Saúde. Documento Política Nacional de Atenção Integral à Saúde do Homem. 2008b.

CARRARA, S.; RUSSO, J. A.; FARO, L. A política de atenção à saúde do homem no Brasil: os paradoxos da medicalização do corpo masculino. Physis, Rio de Janeiro, v. 19, n. 3, p. 659678, 2009. Disponível em: http://www.scielo.br/pdf/physis/v19n3/a06v19n3.pdf. Acesso em: 31 jul. 2019.

CIÊNCIA \& SAÚDE COLETIVA. Rio de Janeiro, v. 10, n. 1, jan-mar, 2005.

DEAN, R. J. Beyond radicalism and resignation: the competing logics for public participation in policy decisions. Policy and Politics, p. 1-17, 2016. Disponível em: http://www.ingentaconnect. com/contentone/tpp/pap/2017/00000045/00000002/art00006 . Acesso em: 19 jun. 2017.

GOMES, R.; SCHRAIBER, L. B.; COUTO, M. T. O homem como foco da Saúde Pública. Ciênc. saúde coletiva, Rio de Janeiro, v. 10, n. 1, p. 4, mar. 2005. Disponível em: http://www. scielo.br/pdf/csc/v10n1/a01v10n1.pdf. Acesso em 16 out. 2017.

LACLAU, E.; MOUFFE, C. Hegemonia e estratégia socialista: por uma política democrática radical. Tradução de Joanildo A. Burity, Josias de Paula Jr., Aécio Amaral. São Paulo: Intermeios; Brasília: CNPq, 2015. 288p. 
LEAL, A. F.; FIGUEIREDO, W. S.; NOGUEIRA-DA-SILVA, G. S. O percurso da Política Nacional de Atenção Integral à Saúde dos Homens (PNAISH), desde a sua formulação até sua implementação nos serviços públicos locais de atenção à saúde. Ciênc. saúde coletiva, Rio de Janeiro, v. 17, n. 10, out., 2012. Disponível em: <http://www.scielo.br/pdf/csc/v17n10/10.pdf >. Acesso em: 29 abr. 2019.

MARTINS, A. M.; MALAMUT, B. S. Análise do discurso da Política Nacional de Atenção Integral à Saúde do Homem. Saude soc., São Paulo, v. 22, n. 2, jun., 2013. Disponível em: http://www.scielo.br/pdf/sausoc/v22n2/v22n2a14.pdf. Acesso em: 29 abr. 2019.

MENDONÇA, V. S.; ANDRADE, A. N. A Política Nacional de Saúde do Homem: necessidade ou ilusão? Rev. psicol. polít., São Paulo, v. 10, n. 20, dez., 2010. Disponível em <http://pepsic. bvsalud.org/pdf/rpp/v10n20/v10n20a03.pdf>. Acesso em: 29 abr. 2019.

MINAYO, M. C. S. Técnicas de análise de material qualitativo. In: . O desafio do conhecimento: pesquisa qualitativa em saúde. 9ed. São Paulo: Hucitec, 2006. p.303-360.

MOUfFE, C. Sobre o político. Tradução de Fernando Santos. São Paulo: WMF Martins Fontes, 2015.

MÜLLER, R. F.; BIRMAN, J. Negociando saberes e poderes: a Política Nacional de Atençáo Integral à Saúde do Homem e a Sociedade Brasileira de Urologia. Hist. cienc. saude-Manguinhos, Rio de Janeiro, v. 23, n. 3, jul.-set., 2016. Disponível em: http://www.scielo.br/pdf/hcsm/ v23n3/0104-5970-hcsm-S0104-59702016005000011.pdf. Acesso em: 8 dez. 2017.

RICHARDSON, N.; CARROLL, P. C. Getting men's health onto a policy agenda: charting the development of a National Men's Health Policy in Ireland. Journal of Men's Health, v. 6, n. 2, 2009.

RICHARDSON, N. A.; SMITH, J. A. B. National men's health policies in Ireland and Australia: What are the challenges associated with transitioning from development to implementation? Public Health, v. 125, n. 7, 2011.

SPINK, M. J. (Org.). Práticas discursivas e produçâo de sentidos no cotidiano. Rio de Janeiro: Centro Edelstein de Pesquisas Sociais, 2013.

TEMPORÃO, J. G. Discurso de posse do Dr. José Gomes Temporão no cargo de ministro da Saúde em 19 mar. 2007. Disponível em: http://www5.ensp.fiocruz.br/biblioteca/dados/ arq5068.pdf. Acesso em: 4 nov. 2016.

TEO, C. H. et al. A consensus on men's health status and policy in Asia: A Delphi survey. Public Health, v. 129, n. 1, 2015. 


\section{Notas}

${ }^{1}$ Este artigo é resultado da tese intitulada "Participação em construção de políticas de saúde: o caso da Política de Atenção Integral à Saúde do Homem”, defendida em 2018 no Programa de Pós-Graduação em Saúde Pública da Escola Nacional de Saúde Pública Sérgio Arouca/ Fiocruz.

${ }^{2}$ Conforme documentos analisados sobre os Fóruns de Saúde do Homem realizados na Câmara dos Deputados nos anos de 2006 a 2009.

${ }^{3}$ Conforme contrato de serviços com a OPAS BR/CNT/0600649.001, de outubro de 2006.

${ }^{4}$ Conforme Nota Técnica de 25 de março de 2008 da ATSH/MS.

${ }^{5}$ Conforme ata da Centésima Nonagésima Nona Reuniáo Ordinária realizada em 8 e 9 de julho de 2009. ${ }^{6}$ A.P. A Hemmi participou da coleta e análise dos dados, discussão e redação do artigo. T.W.F. Baptista colaborou no planejamento e na redação do artigo. M. Rezende participou da redação e da revisão crítica do texto. 


\section{Abstract}

\section{The National Men's Health policy making process}

This paper analyzes the National Men's Health policymaking process to recognize the participation of the various social stakeholders in the formulation of this public policy. To this end, this work seeks to identify the events that preceded the construction of the document, the strategies used to promote the participation of different interest groups and the mechanisms for the agreement and decision-making process. Institutional documents, academic references and interviews with agents participating in the process were analyzed. We identified that the Policy's intention emerged from the action of the Brazilian Society of Urology. The Ministry of Health drew other agents closer to the political process, but the biomedical perspective prevailed. The agents' participation built on knowledge transfer, with little room for confronting conflicts in the construction of politics, although the final document had been released as an expression of consensus. The contradictions and disputes around the definition of men's health have been silenced.

Keywords: public policy; social participation; men's health; health policy. 